\title{
Effect of Action Observation Training Using Y-Balance on Balance Capability in Young Adults
}

\author{
Sung Min Son'1, Kyung Woo Kang ${ }^{2}$ \\ 'Department of Physical Therapy, College of Health Science, Cheongju University, Cheongju; ${ }^{2}$ Department of Physical Therapy, Yeungnam University \\ College, Daegu, Korea
}

Purpose: This study examined the effects of action-obsenvation training using the Y-Balance on the balance ability of young adults.

Methods: Thirty-four healthy adults were randomized into an action-observation group $(n=17)$ or a control group $(n=17)$. All subjects performed the Y-Balance test before and after watching the video. The action observation group watched a video of someone performing a Y-Balance test, and the control group watched a video of scenery unrelated to the training. The subjects were measured through a Y-Balance test for both the length of the legs extended in three directions and the Y-balance composite score.

Results: A significant difference in the Y-balance composite score was observed between the two groups. A part of the direction of the extended leg in the action observation group was increased significantly (posteromedial direction of the right leg, posterolateral direction of the right leg, posteromedial direction of left leg) compared to the control group.

Conclusion: These results suggest that action observation training only could help improve balance.

Keywords: Action observation training, Y-balance test, Balance training

\section{서 론}

전통적으로 균형은 노인의 문제로 취급되는 경향이 있으며, 특히 노 인들의 낙상예방을 위해 필수적으로 훈련되어야 할 요소로 알려져 왔다. 균형의 문제는 노인 인구의 증가와 더불어 중요한 이슈로 자리 잡고 있는데, 한국 사회에서도 65 세 이상의 노인인구는 급속도로 증 가하고 있다. 1.21970 년 이후 30 여년간 $3.1 \%$ 에서 $7.6 \%$ 로 2 배가까이 증가 하고 있으며, 2030년에는 23.1\%까지 증가할 것으로 보는 연구도 있고, 2000년에 전체인구의 7\%였던 노인인구가 2018년 14\%로, 다시 2026년 에는 $20 \%$ 로 증가할 것으로 보는 연구도 있다. ${ }^{4}$ 그러나 최근에는 균형 의 문제를 더 이상의 노인의 문제로만 치부하지 않는다. 다양한 스포 츠, 레크리에이션 및 운동을 일상으로 하는 젊은 인구에서도 외상성 및 과사용으로 인해 균형의 손상이 발생되고 있다. ${ }^{5}$ 전 연령층에서 발 생할 수 있는 균형의 손상을 방지하기 위해서는 낙상을 예방하고 하 지 근골격계의 상태를 손상시키지 않아야 하며 간단하면서도 검증 된 균형 평가 방법이 필요하다.5,6

최소한의 장비로 동적균형을 측정할 수 있는 검사 방법으로 The
Star Excursion Balance Test (SEBT)가 있다. 이 검사는 한 쪽 다리로 선 채 반대쪽 다리로 8 방향으로 뻗어 균형 능력을 측정하는 것으로, 특 히 만성의 발목 문제를 가진 사람들에게 타당도를 보인 검사방법이 다. ${ }^{78}$ 그러나 SEBT가 8 방향을 측정하는 것에 대해 방향의 중복성을 지적하여 더 나은 시간 효율을 얻을 목적으로 3 방향의 균형 한계와 균형 비대칭을 검사하는 Y-균형 검사(The Y-balance test, YBT)가 개발 되었다.910 $\mathrm{Y}$-균형 검사는 한 다리로만 서서 반대쪽 다리를 앞쪽, 뒤-안 쪽, 뒤-가쪽의 세 방향으로 뻗은 뒤, 뼏은 거리를 합한 후 다리 길이 (limb length)의 3 배 값으로 나눈 후 백분율을 구하는 검사이다. 이 검 사는 평가자내 및 평가자간 신뢰도가 모두 높은 검사방법으로 알려 져 있다. ${ }^{5}$ 초기에 Y-균형 검사는 부상결과를 예측하는 검사로 많이 사용되었는데, $\mathrm{Y}$-균형 검사 결과 좌우 $4 \mathrm{~cm}$ 이상의 비대칭 결과가 나 타난 경우 하지의 부상 위험은 2.5 배 높다는 연구결과가 있었다. ${ }^{6}$ 그 밖에 Y-균형 검사를 자세 안정성 지표로 활용할 수 있다는 연구도 있 으며, 엉덩관절 주위 근력이나 근활성도와의 연관성이 있다는 연구 들도 있어 다양한 지표로의 활용 가능성을 보여주고 있다.11-13

다른 사람의 동작 수행을 관찰하는 것은 "거울뉴런(mirror neu-
Received Mar 5, 2020 Revised Apr 9, 2020

Accepted Apr 14, 2020

Corresponding author Kyung Woo Kang

E-mail zephyr0001@hanmail.net
Copylight (C)2020 The Korean Society of Physical Therapy

This is an Open Access article distribute under the terms of the Creative Commons Attribution Non-commercial License (https:// creativecommons.org/license/by-nc/4.0.) which permits unrestricted non-commercial use, distribution, and reproduction in any medium, provided the original work is properly cited. 
rons)"을 활성화시키는 것으로 알려져 있다. ${ }^{14}$ 인간에게서 동작 관찰 (action observation)은 일차운동겉질(primary motor cortex, M1)을 흥 분시켜 동작을 이해하는 과정과 유사한 인지 절차를 만들어내고 운 동 학습, 모방 학습, 동작 기억 등의 결과를 나타낸다.15,16 이전에 동작 을 관찰하거나 동작을 상상하는 것이 운동 학습에 영향을 미친다는 연구결과가 다수 발표되었고, ${ }^{17-19}$ 뇌졸중 환자를 위한 균형 훈련에 대 한 연구들에서도 동작 관찰을 통한 운동 학습의 효과가 있었음이 보 고되고 있다. ${ }^{20,21}$ 관찰 훈련과 유사한 실험을 통해 균형 능력의 향상 을 이끌어낸 연구가 몇몇 보고되고 있는데, 가상현실을 기반으로 한 훈련이 균형 능력을 향상시켰다는 연구가 있고, ${ }^{22}$ 거울뉴런 시스템 기 반의 동작 관찰이 뇌졸중 환자의 하지 근활성도와 균형을 향상시킨 다는 보고도 있다.23

노인을 포함한 여러 연령층에서 손상 등으로 인한 균형의 손실이 나 타났을 때 이를 향상시키기 위한 방법이 필요한 실정이다. 균형향상을 위해 직접 훈련하기 전에 동작 관찰에 의한향상을 이끌어낸다면 훈련 의 효율을 높일 수 있을 뿐만 아니라 훈련 중 낙상에 의한 손상도 예방 할 수 있다. ${ }^{24}$ 동작 관찰은 직접 훈련하지 않더라도 근력의 향상, 운동 학습 등의 효과를 기대할 수 있으므로, 동작을 관찰하는 것만으로 균 형능력 향상에 얼마나 영향을 끼치는지에 대해 알아볼 필요가 있다.5 따라서 본 연구는 젊은 성인을 대상으로 $\mathrm{Y}$-균형 검사를 사용한 동작 관찰훈련이 균형 능력에 미치는 영향에 대해 알아보고자 한다.

\section{연구 방법}

\section{1. 연구 대상}

본 연구의 대상자는 건강한 성인 남녀 34 명을 대상으로 실시하였으 며, 실험 그룹과 대조 그룹으로 각각 17 명씩 무작위 배정으로 분류하 였다. 모든 대상자는 실험 전에 본 연구에 대한 목적과 훈련 방법에 대한 설명을 충분히 듣고 자발적으로 본 연구에 참여에 동의하였으 며, 대상자 모두 연구 참여 동의서에 서명을 하였다. 대상자 선별 기준 은 실험에 영향을 줄 수 있는 신체적 결함 혹은 신경학적 결함이 없 는 자로 선정하였으며, 대상자의 제외 기준은 다음과 같다. 1) 최근 3 개월간 하지의 통증 및 근골격계 문제가 있는 자, 2) 전정 기관에 문제 혹은 어지러움증이 있는 자, 3) 중추신경계 및 말초신경계의 결함이 있는 자, 4 ) 최근 3 개월간 체계적인 운동 훈련을 하고 있는 자.

\section{2. 평가 도구 및 측정 방법}

본 연구에서 균형 능력을 평가하기 위해 $\mathrm{Y}$-균형 검사를 사용하였고, 자체 제작한 Y-균형 검사 장비를 사용하였다. Y-균형 검사 장비는 중 앙에 고정된 나무상자를 설치하여 지지하는 다리가 위치할 수 있도 록 하였고, 앞쪽(anterior), 뒤-안쪽(posteromedial), 뒤-가쪽(posterolat-

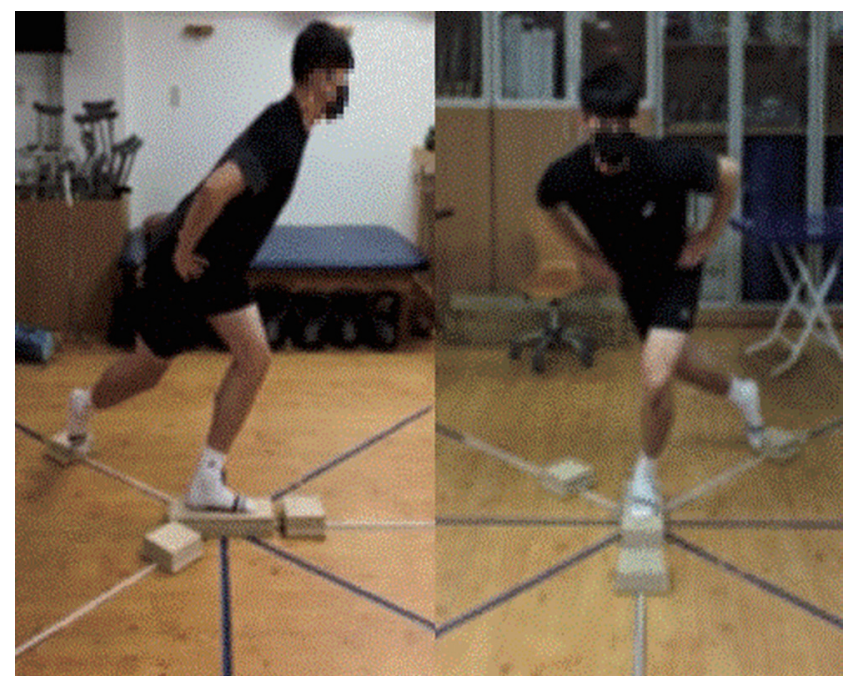

Figure 1. Y-Balance test.

eral) 방향 레일 위에 움직이는 나무 상자를 설치하여 반대쪽 다리가 이동할 때 거리를 측정할 수 있도록 설계하였다(Figure 1).

대상자는 연구자의 충분한 설명을 들은 후 연구자의 지시에 따라 한쪽 발로 지지한 상태에서 반대쪽 발을 이용해 앞쪽, 뒤-안쪽, 뒤-가 쪽의 세 방향으로 최대한 멀리 다리를 뻗도록 유도하였으며, 세 방향 에 대한 순서는 무작위로 실시하였다. 측정 동안 지지하는 다리의 발 끝이 나무 상자 위에 설치한 선 중앙에 위치시키고, 양손은 골반 위 에 위치시켰다. 이동 거리의 측정은 지지하는 다리의 나무 상자 위에 설치한 중앙 선에서 이동한 나무 상자까지의 거리를 줄자를 이용하 여 측정하였다.

$\mathrm{Y}$-균형 검사 평가는 측정 방법의 이해와 학습효과를 최소화하기 위해 측정 전 3 번의 연습 기회를 제공하였고, 중재 전과 중재 후 각각 세 번씩 측정한 값의 평균값을 사용하였다. 검사 도중 지지하는 다리 가 나무 상자 아래로 떨어지거나 움직이는 다리가 바닥에 닿을 경우 혹은 움직이는 다리가 시작 자세로 돌아오지 못하는 경우에는 실패 로 간주하여 재측정을 실시하였다. 각 측정 시마다 근 피로를 방지하 기 위해 30 초간의 휴식 후 측정하였다. 검사를 실시하는 동안 외부 자극에 따른 영향을 최소화하고 대상자가 집중을 유지할 수 있도록 외부와 밀폐된 환경에서 실시하였다.

측정된 Y-균형 검사 점수는 종합 점수(composite score)로 값으로 조정되었다. 종합 점수는 앞쪽, 뒤-안쪽, 뒤-가쪽의 이동 거리를 합한 후 다리 길이(limb length)의 3 배 값으로 나눈 백분율을 구한 값을 의 미한다. ${ }^{5}$

Composite score $=($ anterior + posteromedial + posterolateral $) /(3 \times$ limb length $)$ 모든 대상자의 다리 길이는 바로 누운 자세에서 위앞엉덩뼈가시 (anterior superior iliac crest)에서 안쪽 복사뼈(medial malleolus)까지의 거리를 측정하였다. ${ }^{26}$ 


\section{3. 동작 관찰 훈련}

본 연구에서 동작 관찰 훈련의 효과를 확인하기 위해 실험 그룹과 대 조 그룹에게 각각 다른 영상을 제공하였다. 실험 그룹에서는 직접 $\mathrm{Y}-$ 균형 검사를 실시하는 모습을 촬영한 동영상을 관찰하도록 하였고, 대조 그룹은 균형 검사 및 훈련과 관계없는 풍경 영상을 제공하였다. 동작 관찰 훈련 동영상은 Y-균형 검사 방법을 잘 이해하고 충분한 시 간 동안 Y-균형 검사를 연습한 대상자가 양측 다리를 사용하여 훈련 을 실시하는 모습을 앞쪽, 뒤쪽, 양 가쪽에서 촬영하여 대상자들에게 관찰할 수 있도록 제공하였다. 동작 관찰 동영상은 2 분으로 구성되었 고, 5 회 반복 재생하여 10 분 동안 동영상을 시청할 수 있도록 제작하 였다. 두 그룹의 대상자들은 조용한 환경에서 동일하게 매일 10 분간 주 5 회 총 3 주 동안 각각의 영상을 시청하였다.

\section{4. 분석 방법}

두 그룹 간의 나이, 키, 몸무게 및 다리 길이와 같은 일반적 특성은 독 립표본 t-검정(independent t-test)을 이용하여 비교하였고, 정규성 검 정은 Kolmogorove-Sminov 검정을 실시하였다. 두 그룹의 중재 방법에 따른 전-후 효과 비교를 위해 이요인 반복 측정 분산 분석(two way re-

Table 1. The general characteristics of subjects.

\begin{tabular}{lccc}
\hline Variables & $\begin{array}{c}\text { Experimental } \\
\text { group }(n=17)\end{array}$ & $\begin{array}{c}\text { Control group } \\
(n=17)\end{array}$ & p-value \\
\hline Gender (male/female) & $7 / 10$ & $8 / 9$ & \\
Age (yr) & $22.53 \pm 1.23$ & $22.23 \pm 1.52$ & 0.540 \\
Height (cm) & $165.00 \pm 9.79$ & $168.00 \pm 9.73$ & 0.377 \\
Weight (kg) & $58.06 \pm 12.06$ & $60.53 \pm 11.62$ & 0.547 \\
Right limb length $(\mathrm{cm})$ & $85.24 \pm 6.47$ & $87.09 \pm 6.58$ & 0.414 \\
Left limb length $(\mathrm{cm})$ & $85.38 \pm 6.36$ & $87.21 \pm 6.42$ & 0.414 \\
\hline
\end{tabular}

Values are presented as mean \pm standard deviation.

Table 2. Pre-test score and post- of Y-Balance in both groups

\begin{tabular}{|c|c|c|c|c|}
\hline \multicolumn{3}{|c|}{ Parameter } & \multirow{2}{*}{$\begin{array}{c}\begin{array}{c}\text { Experimental } \\
\text { group }(n=17)\end{array} \\
43.45 \pm 5.77\end{array}$} & \multirow{2}{*}{$\begin{array}{c}\text { Control } \\
\text { group }(n=17) \\
44.16 \pm 6.02\end{array}$} \\
\hline Right & AN & Pre & & \\
\hline & & Post & $45.38 \pm 6.70$ & $44.04 \pm 5.59$ \\
\hline & PM & Pre & $48.03 \pm 11.87$ & $49.27 \pm 11.81$ \\
\hline & & Post & $56.97 \pm 11.30$ & $51.87 \pm 11.34$ \\
\hline & $\mathrm{PL}$ & Pre & $52.57 \pm 11.17$ & $51.98 \pm 10.14$ \\
\hline & & Post & $61.20 \pm 9.79$ & $55.77 \pm 9.86$ \\
\hline \multirow[t]{6}{*}{ Left } & AN & Pre & $42.20 \pm 6.02$ & $42.76 \pm 6.03$ \\
\hline & & Post & $44.99 \pm 6.14$ & $43.89 \pm 5.70$ \\
\hline & PM & Pre & $48.85 \pm 11.54$ & $49.55 \pm 11.89$ \\
\hline & & Post & $57.33 \pm 11.74$ & $52.81 \pm 12.86$ \\
\hline & $\mathrm{PL}$ & Pre & $54.42 \pm 12.74$ & $52.60 \pm 9.01$ \\
\hline & & Post & $59.87 \pm 9.25$ & $54.99 \pm 10.57$ \\
\hline
\end{tabular}

Values are presented as mean \pm standard deviation.

AN: Anterior, PM: Posteromedial, PL: Posterolateral. peated ANOVA)을 사용하였으며, 교호작용(cross effect)이 나타났을 경우 전-후 차 값을 이용하여 독립표본 $\mathrm{t}$ 검정을 실시하였다. 그룹 내 전-후 비교를 위해 대응표본 t-검정(paired t-test)을 사용하였다.

\section{결 과}

본 연구에 참여한 대상자는 총 34 명으로서 동작 관찰을 시청한 실험 그룹과 일반적인 풍경을 시청한 대조 그룹 각각 17 명씩 할당되었다. 대상자들의 나이, 키, 몸무게 및 다리 길이와같은 일반적인 특성에서 그룹 군 사이에 유의한 차이는 없었다( $\mathrm{p}>0.05)$. 본 연구에 참여한 대 상자들의 일반적인 특성은 Table 1에 제시하였다. 훈련 전-후 앞쪽 방 향, 뒤안쪽 방향과 뒤가쪽 방향으로 이동한 오른쪽과 왼쪽 다리의 이 동 거리는 Table 2에 제시하였다.

훈련 전-후 오른쪽과 왼쪽 Y-균형 검사 종합점수(composite score)에 대한 그룹 내 비교에서는 두 그룹 모두에서 유의한 차이를 나타났다 $(\mathrm{p}<0.05)$ (Table 3). 훈련 전-후 두 그룹 간 비교를 위해 이요인 반복측정 분산분석을 통해 확인하였다. 훈련 전-후 두 그룹 간 비교에서 오른쪽 과 왼쪽 Y-균형 검사 종합점수에서 두 그룹 사이에서 유의한 차이가 나타났으며 $(\mathrm{p}=0.003, \mathrm{p}=0.005)$, 실험 전-후 값차이를 통한 사후검정 비교에서도 유의한 차이를 확인하였다 $(\mathrm{p}=0.003, \mathrm{p}=0.005)$ (Table 3).

\section{고 찰}

본 연구는 젊은 성인을 대상으로 Y-균형 검사를 사용한 동작 관찰훈 련이 균형능력에 미치는 영향에 대해 알아보고자 하였다. Y-균형 검 사 종합점수에서는 실험 전과 후에 유의미한 점수 차이를 보여 동작 관찰훈련만으로 균형 능력의 향상을 보일 수 있음을 나타냈다. 양쪽 다리의 세 방향에 대해 뻗친 길이의 변화는 동작 관찰훈련 후 전반적 으로 뻗친 길이가 늘어난 것으로 나타났지만, 통계학적인 차이는 일

Table 3. Comparison of composite score in both group after intervention

\begin{tabular}{llccc}
\hline Parameter & & $\begin{array}{c}\text { Experimental } \\
\text { group }(n=17)\end{array}$ & $\begin{array}{c}\text { Control } \\
\text { group }(n=17)\end{array}$ & $\begin{array}{c}\text { Group*Time } \\
(\mathrm{p} \text {-value })\end{array}$ \\
\hline Right & Pre & $56.12 \pm 7.92$ & $55.41 \pm 7.13$ & 0.003 \\
& Post & $63.78 \pm 7.37$ & $57.90 \pm 7.03$ & \\
& p-value & $<0.001^{*}$ & $0.021^{*}$ & \\
& Post-Pre diff & $7.66 \pm 5.24^{+}$ & $2.49 \pm 3.99$ & \\
Left & Pre & $56.52 \pm 7.94$ & $55.29 \pm 7.38$ & 0.005 \\
& Post & $63.06 \pm 6.62$ & $57.86 \pm 8.13$ & \\
& p-value & $<0.001^{*}$ & $0.005^{*}$ & \\
& Post-Pre diff & $6.54 \pm 4.26^{+}$ & $2.58 \pm 3.27$ & \\
\hline
\end{tabular}

Values are presented as mean \pm standard deviation.

${ }^{*} p<0.05$ : significant difference between pre and post test, ${ }^{t} p<0.05$ : significant difference compared with the control group. 
부에서만 확인되었다(오른쪽 다리의 뒤-안쪽 방향, 오른쪽 다리의 뒤-가쪽 방향, 왼쪽 다리의 뒤-안쪽 방향).

동작 관찰이 균형 향상과 같이 운동 능력의 향상에 영향을 미치는 것은 동작을 관찰하는 것이 실제로 근육을 수축시키는 것과 같은 일 차운동피질(M1)의 영역을 활성화시키기 때문이라는 견해가 있다. ${ }^{27}$ 몇몇 연구에서 인간이 동작 관찰을 하며 상상을 하게 되면 춤에 대한 시퀀스, 목적 없는(intransitive) 엄지 움직임, 목표물을 조작하는(transitive) 손의 움직임, 보행 등을 수행할 때 실제로 감각을 받아들이고 움직임에 대한 명령을 내리는 뇌 영역을 활성화 시키게 된다는 연구 결과들이 이를 뒷받침 해준다. ${ }^{28-31} \mathrm{Y}$-균형 검사는 움직임이 발생하는 과정 속에서 균형을 유지해야 하는 검사이므로 하지 근육의 수의적 조절을 요한다. ${ }^{5}$ 본 연구결과에서 동작 관찰 후 $\mathrm{Y}$-균형 검사의 종합점 수에서 유의미한 향상을 나타낸 것은, 피험자가 동작을 관찰하는 동 안 움직임의 시퀀스가 어떻게 일어나는지를 보고 수의적 움직임에 대한 조절을 상상하게 되므로 일차운동피질과 같은 뇌 영역이 활성 화된 이유로 생각된다. ${ }^{27}$

동작 관찰 훈련은 임상에서 뇌졸중 환자나 파킨슨 환자와같이 거 동이 자유롭지 않은 환자들에게 많이 적용되고 있다. 동작 관찰이 실 제 훈련이 아니므로 균형 훈련 중 발생할 수 있는 낙상 등을 예방할 수 있는 까닭이다. 임상에서 동작 관찰을 통해 보행이나 균형을 향상 시킨 몇몇 연구들이 이를 뒷받침하고 있다. ${ }^{20,21,24} \mathrm{Y}$-균형 검사는 평소 사람들이 많이 하지 않는 동작인데, 이와 같이 새롭고 생소한 동작을 학습하는데 있어 동작 관찰이 좋은 운동 학습 전략이라고 밝힌 연구 가 있고, 특히 이 연구는 동작 관찰이 운동 학습 초기에 더 우수한 결 과를 낸다고 밝혔다. ${ }^{32}$ 이는 Y-균형 검사가 많은 사람에게 새로운 동 작일 수 있으므로, 처음 실시하기 이전에 동작 관찰을 한 실험그룹이 더 좋은 결과를 낼 수 있다는 점을 시사한다. 본 연구 결과에서 뻗친 길이의 변화를 비교했을 때, 양쪽 다리 모두 앞쪽으로 뻗는 동작에서 는 유의한차이를 내지 못한 것도 이와 유사한 맥락으로 이해할 수 있 다. 상대적으로 한쪽 다리를 앞쪽으로 뻗는 움직임은 런지(lunge)라 는 운동 자세와 유사하여 우리에게 익숙하나, 다리를 뒤-가쪽 또는 뒤-안쪽으로 뻗는 동작은 흔하게 수행하는 동작이 아니다. ${ }^{33}$ 본 연구 결과에서도 오른쪽 다리의 뒤-안쪽 방향, 오른쪽 다리의 뒤-가쪽 방 향, 왼쪽 다리의 뒤-안쪽 방향으로 뻗는 동작들을 수행할 때 실험그 룹에서 유의한 차이를 보인 것은, 이러한 동작이 상대적으로 생소한 동작이기 때문에 동작 관찰을 통해 더 나은 향상을 보인 것으로 생각 된다.

본 연구의 결과로 동작을 관찰하는 것만으로도 Y-균형 검사에서 유의한 향상을 나타낼 수 있는 것을 알 수 있었다. 이러한 결과는 특 히 세 방향으로 다리 뻗기 중 뒤-가쪽 및 뒤-안쪽으로 다리를 뻗는 것 과 같이 생소한 동작을 할 때 더욱 뚜렷하게 나타났다. 본 연구에는
몇 가지 제한점이 있었다. 본 연구에서는 관찰훈련 도구로 Y-균형 검 사를 사용하였고, 균형 향상의 결과를 알아보기 위한 측정도구 역시 $\mathrm{Y}$-균형 검사를 사용하였기에 다양한 균형 평가를 할 수 없었다. 그리 고 젊고 건강한 피험자들을 대상으로 실험하여 전 연령층에 일반화 하기 어렵고, 실제 균형에 문제가 있는 사람에게 적용하지 않아 임상 에 적용하기 어려워 추가적인 연구가 필요할 것으로 보인다. 향후 연 구에서는 손상 등으로 인해 균형 능력이 저하된 자 혹은 뇌졸중, 파 킨슨병 환자들과 같이 기저질환이 있는 환자들을 대상으로도 연구 가 진행되어야 할 것이다.

\section{참고문헌}

1. Fahlstrom G, Kamwendo K, Forsberg J et al. Fall prevention by nursing assistants among community-living elderly people. A randomised controlled trial. Scand J Caring Sci. 2018;32(2):575-85.

2. Bae J, Cho SI. effects of community-based comprehensive fall prevention program on muscle strength, postural balance and fall efficacy in elderly people. J Korean Acad Nurs. 2014;44(6):697-707.

3. Sohng KY, Moon JS, Song HH et al. Risk factors for falls among the community-dwelling elderly in korea. Taehan Kanho Hakhoe Chi. 2004;34(8):1483-90.

4. Yoon HS. Korea: Balancing economic growth and social protection for older adults. Gerontologist. 2013;53(3):361-8.

5. Shaffer SW, Teyhen DS, Lorenson CL et al. Y-balance test: A reliability study involving multiple raters. Mil Med. 2013;178(11):1264-70.

6. Plisky PJ, Rauh MJ, Kaminski TW et al. Star excursion balance test as a predictor of lower extremity injury in high school basketball players. J Orthop Sports Phys Ther. 2006;36(12):911-9.

7. Akbari M, Karimi H, Farahini $\mathrm{H}$ et al. Balance problems after unilateral lateral ankle sprains. J Rehabil Res Dev. 2006;43(7):819-24.

8. Hale SA, Hertel J, Olmsted-Kramer LC. The effect of a 4-week comprehensive rehabilitation program on postural control and lower extremity function in individuals with chronic ankle instability. J Orthop Sports Phys Ther. 2007;37(6):303-11.

9. Kinzey SJ, Armstrong CW. The reliability of the star-excursion test in assessing dynamic balance. J Orthop Sports Phys Ther. 1998;27(5):356-60.

10. Gribble PA, Kelly SE, Refshauge KM et al. Interrater reliability of the star excursion balance test. J Athl Train. 2013;48(5):621-6.

11. Walaszek R, Chwala W, Walaszek K et al. The assessment of the relationships between body posture indices and the y-balance test results in the adolescents. Acta Bioeng Biomech. 2018;20(2):149-57.

12. Wilson BR, Robertson KE, Burnham JM et al. The relationship between hip strength and the y balance test. J Sport Rehabil. 2018;27(5):445-50.

13. Yam TTT, Fong SSM. Y-balance test performance and leg muscle activations of children with developmental coordination disorder. J Mot Behav. 2019;51(4):385-93.

14. Gallese V, Fadiga L, Fogassi L et al. Action recognition in the premotor cortex. Brain. 1996;119 (Pt2):593-609.

15. Gangitano M, Mottaghy FM, Pascual-Leone A. Phase-specific modulation of cortical motor output during movement observation. Neurore- 
port. 2001;12(7):1489-92.

16. Iacoboni M, Molnar-Szakacs I, Gallese V et al. Grasping the intentions of others with one's own mirror neuron system. PLoS Biol. 2005;3(3):e79.

17. Kawasaki T, Tozawa R, Aramaki H. Effectiveness of using an unskilled model in action observation combined with motor imagery training for early motor learning in elderly people: A preliminary study. Somatosens Mot Res. 2018;35(3-4):204-11.

18. Bisio A, Bassolino M, Pozzo T et al. Boosting action observation and motor imagery to promote plasticity and learning. Neural Plast. 2018; 2018:8625861.

19. Jayasinghe SAL. The role of sensory stimulation on motor learning via action observation: A mini review. J Neurophysiol. 2019;121(3):729-31.

20. Park EC, Hwangbo G. The effects of action observation gait training on the static balance and walking ability of stroke patients. J Phys Ther Sci. 2015;27(2):341-4.

21. Lee HJ, Kim YM, Lee DK. The effects of action observation training and mirror therapy on gait and balance in stroke patients. J Phys Ther Sci. 2017;29(3):523-26.

22. Prasertsakul T, Kaimuk P, Chinjenpradit W et al. The effect of virtual reality-based balance training on motor learning and postural control in healthy adults: A randomized preliminary study. Biomed Eng Online. 2018;17(1):124.

23. Son YL, Kim JW. The effects of mirror neuron system-based self-observation training on lower limb muscle activity and dynamic balance in patients with chronic stroke. J Phys Ther Sci. 2018;30(10):1241-44.

24. Caligiore D, Mustile M, Spalletta G et al. Action observation and motor imagery for rehabilitation in parkinson's disease: A systematic review and an integrative hypothesis. Neurosci Biobehav Rev. 2017;72:210-22.
25. La Touche R, Herranz-Gomez A, Destenay L et al. Effect of brain training through visual mirror feedback, action observation and motor imagery on orofacial sensorimotor variables: A single-blind randomized controlled trial. J Oral Rehabil. 2020.

26. Beattie P, Isaacson K, Riddle DL et al. Validity of derived measurements of leg-length differences obtained by use of a tape measure. Phys Ther. 1990;70(3):150-7.

27. Todorov E. Direct cortical control of muscle activation in voluntary arm movements: A model. Nat Neurosci. 2000;3(4):391-8.

28. Cross ES, Hamilton AF, Grafton ST. Building a motor simulation de novo: Observation of dance by dancers. Neuroimage. 2006;31(3):125767.

29. Macuga KL, Frey SH. Neural representations involved in observed, imagined, and imitated actions are dissociable and hierarchically organized. Neuroimage. 2012;59(3):2798-807.

30. Wang C, Wai Y, Weng Y et al. The cortical modulation from the external cues during gait observation and imagination. Neurosci Lett. 2008; 443(3):232-5.

31. Nedelko V, Hassa T, Hamzei F et al. Action imagery combined with action observation activates more corticomotor regions than action observation alone. J Neurol Phys Ther. 2012;36(4):182-8.

32. Gatti R, Tettamanti A, Gough PM et al. Action observation versus motor imagery in learning a complex motor task: A short review of literature and a kinematics study. Neurosci Lett. 2013;540:37-42.

33. Kang MH, Lee DK, Park KH et al. Association of ankle kinematics and performance on the $y$-balance test with inclinometer measurements on the weight-bearing-lunge test. J Sport Rehabil. 2015;24(1):62-7. 